\title{
CRANIOPHARYNGIOMA IN THE ELDERLY
}

\author{
BY \\ R. W. ROSS RUSSELL* and J. B. PENNYBACKER \\ From the Departments of Neurology and Neurological Surgery, Radcliffe Infirmary, Oxford
}

\begin{abstract}
Although craniopharyngiomas comprise only a small proportion of intracranial tumours, by virtue of a unique situation close to what Cushing called the mainspring of primitive existence, they have an interest and importance out of proportion to their numbers. Since the tumours are congenital it is not surprising that the majority should present early in life, and many descriptions have been given to the effects produced in children and young adults. It used to be thought that the finding of a craniopharyngioma in an older patient was a rarity, but it now appears that an appreciable proportion of patients have their first symptoms after the age of 40 , and that important differences exist between these and younger patients. In chil-
\end{abstract} dren there are two main syndromes: first, visual failure from compression of the optic nerve and chiasm, and secondly, symptoms and signs of increased intracranial pressure such as headache, papilloedema, and separation of the cranial sutures without specific visual field defects. This latter group results from obstruction of the third ventricle by the tumour. Evidence of hypothalamic and pituitary damage, as shown by various forms of endocrine or growth abnormality, is common, and radiological calcification is often seen. In adults there is much less tendency for the tumour to obstruct the flow of cerebrospinal fluid and the incidence of endocrine abnormality also falls sharply. Visual failure from chiasmal compression remains common, and mental disturbance, a rare feature in young patients, becomes of increasing importance. It is with these two features that this report is chiefly concerned.

\section{Clinical Material}

Between the years 1938 and 1959 in the records of the Departments of Neurological Surgery and Neurology at the Radcliffe Infirmary, Oxford, there were 46 patients in whom a diagnosis of craniopharyngioma was proved at operation or necropsy. There were a further 22 in whom the diagnosis was

*E. G. Fearnsides scholar, University of Cambridge. made on the combination of radiological and clinical findings. Of this total of 68 patients, 24 were middle aged or elderly. There were six in the fifth decade, nine in the sixth decade, eight in the seventh decade, and one in the eighth, the average age of these patients being 57.4 years. There were 11 women and 13 men. The diagnosis was confirmed by operation or necropsy in 18 , and in the remaining six was made on the clinical and radiological findings.

Fourteen patients came under observation because of visual failure with or without headaches, eight because of mental disturbance, one because of seizures, and one because of a radiograph for an unrelated condition.

The majority of patients had symptoms for months or years before seeking advice and in three patients there was a history of recent head injury.

Details of the visual symptoms and signs are set out below.

Visual Failure.-Visual failure was the commonest symptom in this group of patients, and of 24 patients only one had normal visual acuity with full fields. It was not uncommon, however, for visual failure to occur without the patient's knowledge either because central vision was retained at least in one eye, or because of advanced mental symptoms. Four patients with dementia who denied visual symptoms were found to have abnormal acuity or fields.

The duration of visual symptoms before the patient sought advice was very variable, but in the majority (12 patients) it was between six months and two years. Six patients had symptoms for two to five years before seeking advice and one for over 10 years. To the majority of patients visual failure had seemed slowly progressive but marked fluctuation in the visual state both subjectively and objectively was a notable feature in seven cases. In one of these (Case 2) acuity was measured under identical conditions over the space of six months and the acuity at two-monthly intervals was on the right side J.8, J.8 and no perception of light; on the left side J.10, J.2, J.16. 
TABLE I

SURGICAL TREATMENT AND FOLLOW-UP

\begin{tabular}{|c|c|c|c|}
\hline $\begin{array}{l}\text { Case } \\
\text { No. }\end{array}$ & Treatment & Outcome & $\begin{array}{l}\text { Duration of Illness } \\
\text { since First Seen }\end{array}$ \\
\hline $\begin{array}{r}1 \\
2 \\
3 \\
4 \\
5 \\
6 \\
7 \\
8 \\
9 \\
10 \\
11 \\
12 \\
13 \\
14 \\
15 \\
16 \\
17 \\
18 \\
19 \\
20 \\
21 \\
22 \\
23 \\
24\end{array}$ & $\begin{array}{l}\text { Partial removal } \\
\text { Aspiration, biopsy } \\
\text { Partial removal } \\
\text { Partial removal } \\
\text { Removal } \\
\text { None } \\
\text { None } \\
\text { None } \\
\text { Partial removal } \\
\text { Partial removal and aspiration } \\
\text { Aspiration, ventriculocisternostomy } \\
\text { Biopsy } \\
\text { Removal } \\
\text { None } \\
\text { Partial removal } \\
\text { Aspiration, ventriculocisternostomy } \\
\text { Partial removal } \\
\text { Removal } \\
\text { Partial removal } \\
\text { Partial removal } \\
\text { None } \\
\text { None } \\
\text { None } \\
\text { Aspiration, ventriculocisternostomy }\end{array}$ & $\begin{array}{l}\text { Dead } \\
\text { Dead, vision improved post-operatively } \\
\text { Alive, no symptoms, mentally alert } \\
\text { Alive, active, mentally normal } \\
\text { Dead } \\
\text { Dead } \\
\text { Alive, vision unchanged, mentally normal } \\
\text { Alive, occasional seizures, no visual change } \\
\text { No information available } \\
\text { Dead } \\
\text { Dead } \\
\text { Alive, slow visual deterioration } \\
\text { Alive } 3 \text { months later } \\
\text { Alive, unchanged, mentally alert } \\
\text { Dead } \\
\text { Dead } \\
\text { Dead } \\
\text { Alive, memory very poor, vision improved post-operatively } \\
\text { Alive, hypopituitary state } \\
\text { Dead, vision improved post-operatively } \\
\text { Alive, organic dementia } \\
\text { Alive, aged but alert } \\
\text { Alive, unchanged } \\
\text { Dead }\end{array}$ & \begin{tabular}{|l|} 
Post-operative \\
15 months \\
1 year \\
5 years \\
3 months \\
1 year \\
3 years \\
3 years \\
1 year \\
1 year \\
7 years \\
No further information \\
10 years \\
Post-operative \\
3 months \\
Post-operative \\
18 years \\
20 years \\
4 years \\
15 years \\
20 years \\
3 months \\
4 months
\end{tabular} \\
\hline
\end{tabular}

The field changes were not uniform and the different types of defect are listed in Table I, which includes all patients on whom reliable quantitative perimetry was done. In the great majority of patients the defect was bitemporal though a considerable difference between the fields in the two eyes was not uncommon. In cases seen early, the bitemporal field defect could be of the depressional or scotomatous variety, the scotomata often being paracentral and terminating sharply at the vertical meridian. The defect began in the upper or lower temporal quadrants with equal frequency. In the scotomatous type peripheral isopters usually showed some temporal depression in addition to the central loss.

One patient had an incomplete bitemporal hemianopia with a central scotoma in one eye and in another case the scotoma was in the lower nasal field. Two patients showed a homonymous defect, in one combined with a paracentral scotoma. The various types of field loss are illustrated in Figs. 1-8.

Changes in the optic discs were less frequent and less reliable than those in acuity or fields. Thus 10 patients had normal fundi with well-marked field changes and a further five showed some pallor of one or both discs, of doubtful significance. In nine cases there was unequivocal optic atrophy and in one bilateral papilloedema.

One patient (Case 8) experienced visual hallucinations of an unformed type occurring two or three times a day. In these he had a similar and arresting impression of vague objects moving on the right side, although it is not clear whether the hallucinations occurred in homonymous fields or were confined to the right eye. He also suffered from sudden falling attacks without warning and these were independent of the visual symptoms. Field charting showed a bitemporal hemianopia of depressional type.

Following partial removal or aspiration of the tumour four patients showed objective evidence of considerable visual improvement, one showed slight improvement, and eight were unchanged or de-i teriorated. Improvement showed no definite correlation with the preexisting optic atrophy but of the five patients who improved four had normalo or near-normal discs, while of the six who showeds no improvement three had normal fundi at the time of operation.

Six patients had no operation and of these one deteriorated rapidly to complete blindness while five showed no change or slow deterioration over years.

Mental Aspects. - In all patients observations were made regarding level of consciousness, orientation, mood, memory, and simple tests of learning and calculation. In 12 patients no defect could be found but the other 12 patients showed various degrees of abnormality (Table I). In four this amounted to a slight or moderate deterioration in recent memory with a tendency to somnolence, apathy, and loss of interest. In eight, however, the mental disturbance was more profound and dominated the clinical picture leading in three cases to admission to mental hospitals. Two of these eight patients have been reported in full (Williams and Pennybacker, 1954) and the remaining case histories are given below.

\section{Case Reports}

Case 4 (U.O.H. 133629).-V.S., an active housewife of 52, experienced a gradual visual blurring affecting the outer halves of her field of vision, first noticed when 


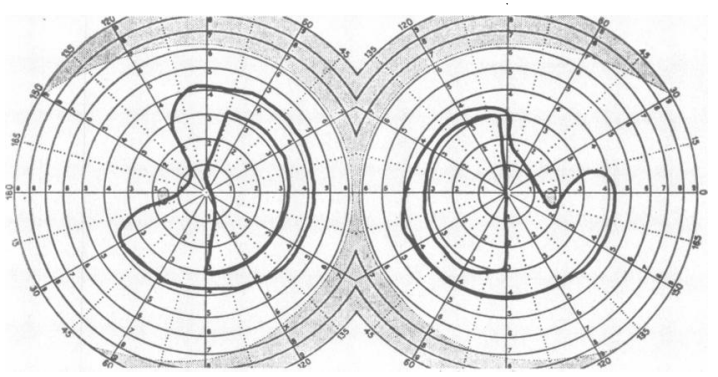

Fig. 1.-Case 2: Bitemporal hemianopia, depressional type. Visual fields to $30 / 2,0002 / 2,000$, white.

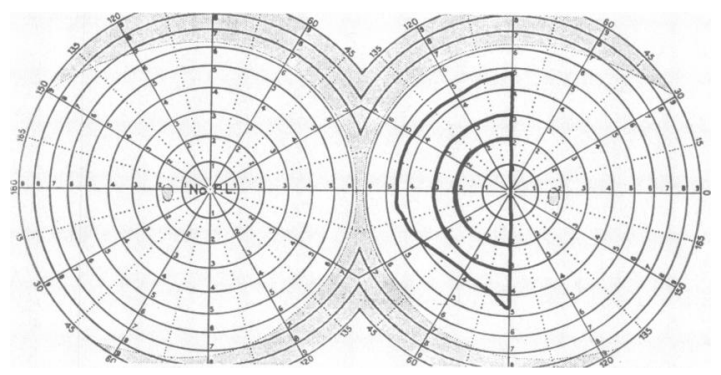

FIG. 3.-Case 19: Right temporal hemianopia and blind left eye. Visual fields to $10 / 330,50 / 2,000,5 / 2,000$ white.

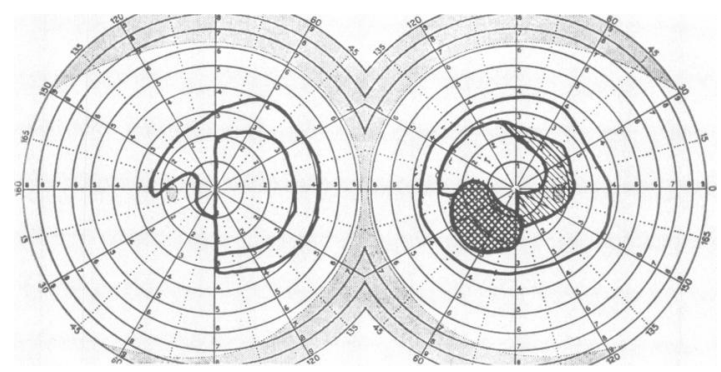

FIG. 5.-Case 13: Incomplete bitemporal hemianopia with large nasal scotoma.

Visual fields to $200 / 2,000,50 / 2,000$ white.

Scotomata to $200 / 2,000$ (absolute and relative).

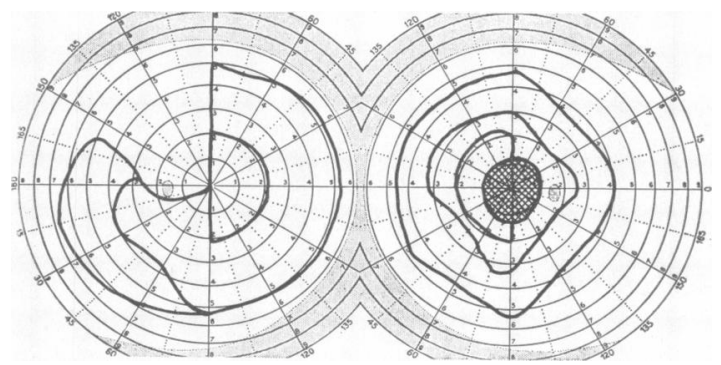

FIG. 7.-Case 3: Left incomplete temporal hemianopia with right central scotoma.

Visual fields to $10 / 330,3 / 330,5 / 2,000$ white (left eye); $5 / 330$, $40 / 2,000,20 / 2,000$ white (right eye).

Scotoma to $40 / 2,000$.

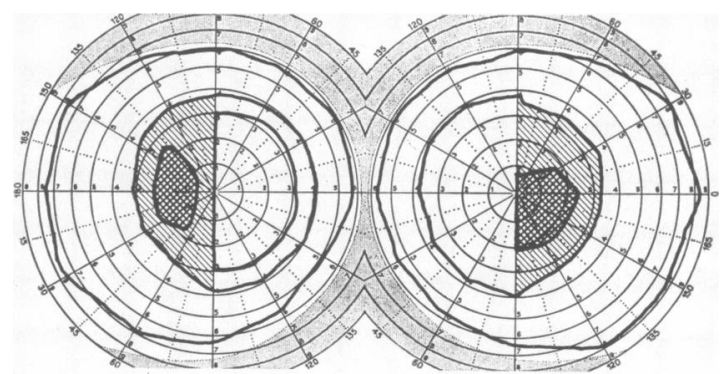

FIG. 2.-Case 18: Bitemporal hemianopia, scotomatous type. Visual fields to $5 / 330,20 / 2,000,10 / 2,000$ white. Scotomata to $20 / 2,000$ (absolute and relative).

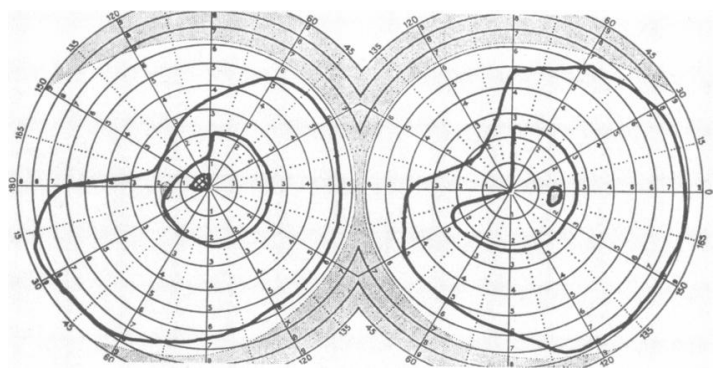

Fig. 4.-Case 6: Homonymous hemianopia with paracentral scotoma Visual fields to $5 / 330,1 / 2,000$ white. Scotoma to $10 / 2,000$.

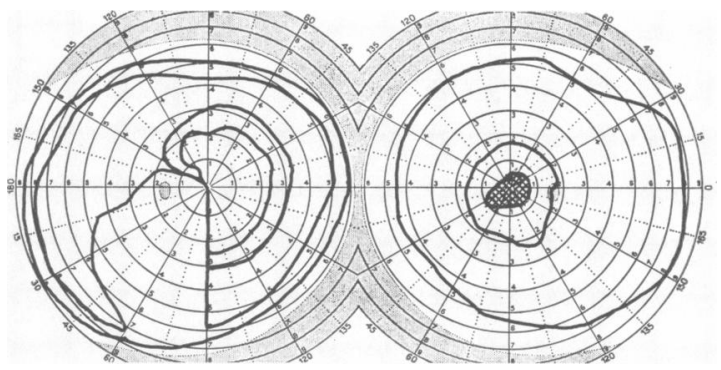

FIG. 6.-Case 24: Left incomplete temporal hemianopia with right central scotoma.

Visual fields (left eye) to $3 / 330,1 / 330,5 / 2,000,2 / 2,000$ white; (right eye) to $3 / 330,10 / 2,000,2 / 2,000$

Scotoma to $10 / 2,000$.

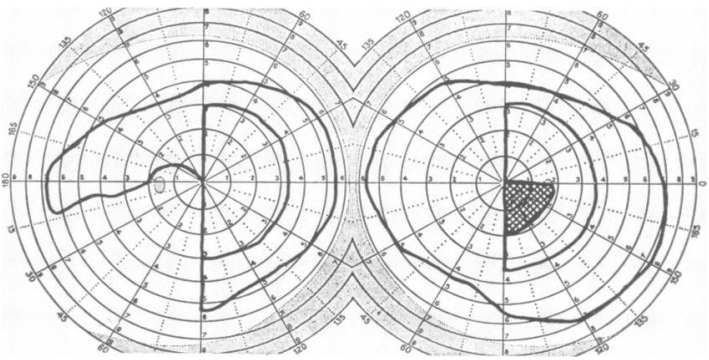

Fig. 8.-Case 17: Bitemporal hemianopia with unilateral scotoma. Visual fields to $3 / 330,2 / 2,000$ white (left eye); $5 / 330,20 / 2,000$ white (right eye).

Scotoma to $20 / 2,000$. 
crossing the road. Central vision was spared and she was able to sew and read. After some months, during which her vision slowly deteriorated, she was noticed to be excessively tired and drowsy and to lose her appetite. She began talking constantly of events in the distant past and became confused about the date and the time of day. When her family asked how she had spent the day, she would invent impossible stories of visits to faraway friends. At times she appeared to believe she was 20 years old and talked of the events of 30 years ago as though they had just occurred. At first these mental symptoms alternated with periods of lucidity but later the confusion became constant. She occasionally complained of headaches and often of excessive cold in the winter; she was always thirsty, drinking 15 cups of tea a day.

Her past health had been excellent although the menses had been a little irregular and she had borne no children. The menopause occurred at the age of 50 and libido had been diminished since that time.

After two years of symptoms, she was admitted to the Radcliffe Infirmary under the care of Dr. E. M. Buzzard and by that time the mental changes were so pronounced that a history had to be obtained from relatives.

She tended to sleep most of the day but when roused would talk incessantly and in a friendly fashion to anyone who would listen. At times she was quite lucid, was able approximately to recall the date, and realized she was ill and in hospital. On another occasion only two hours later she was hopelessly confused, was 10 years behind with the date, and thought she was at home.

She was very distractable and could not attempt simple tests of mental arithmetic. Vocabulary was low average on the Wechsler scale and there was no dysphasia. Memory for remote personal events wis fair but for recent events it was very poor. When asked to repeat a story she altered and distorted it after a few seconds. Learning was also severely affected and she was easily confused and fatigued.

Physical examination revealed a pale and rather obese woman with atrophic dry skin. The scalp hair was fine, dry, and brittle and the body hair of normal distribution apart from moderate facial growth. The breasts and genitalia were normal.

In the central nervous system there was no anosmia and visual acuity was restricted to hand movements in the upper nasal quadrants. The fundi showed bilateral optic atrophy and the pupils reacted sluggishly to light.

There were no other abnormalities.

Investigations.-The cerebrospinal fluid was under normal pressure, with 4 lymphocytes/c.mm. and protein $70 \mathrm{mg}$. $/ 100 \mathrm{ml}$. The Wassermann reaction was negative and the Lange curve $0-0$.

A radiograph of the skull showed that the pituitary fossa was intact but a calcified area lay above and behind the clivus. An air encephalogram showed a large spaceoccupying lesion above the sella in the midline growing into the third ventricle and deforming the anterior horns of the lateral ventricle. Calcification appeared to be outside the mass. There was no hydrocephalus.

Haemoglobin was $100 \%$ and the B.M.R. $19 \%$. The fasting blood sugar level was $79 \mathrm{mg} . / 100 \mathrm{ml}$. The 17-ketosteroids (neutral) were $2 \mathrm{mg}$. 24 hours.

Operation.-The tumour was approached by elevating the right frontal lobe; the optic nerves and anterior border of the chiasma appeared normal. It was seen at the posterior border of the chiasma and appeared to be arising from above rather than from the sella. The tumour was found to be partly cystic and $30 \mathrm{ml}$. of viscid yellow fluid was aspirated. No removal was attempted.

Progress.-Mental testing three days later showed a considerable improvement. The patient was correctly orientated, alert and cooperative, and was able to recall some of the tests she had attempted pre-operatively. Vocabulary learning tests were about the same.

Two days later, however, she began behaving strangely and threw cups and saucers at patients across the ward in the belief that they were poisoning her. She also suffered from visual hallucinations and poured jugs of water over imaginary assailants.

This state of paranoid confusion lasted about 10 days and she then began to improve again. Visual acuity two weeks after the operation was L 6/36, J. 12, R 6/60, J. 20. She was discharged after three weeks.

In the following months her mental state became quite normal and acuity reached VAL 6/9, J.4, VAR 6/60, J.19. Five months later, however, visual failure and headache returned, although she remained mentally clear. Acuity had deteriorated again to hand movements in the nasal upper quadrants only. The tumouro was once more aspirated and vision improved (VAL 6/12, J.14, VAR 6/36, J.18).

She was twice admitted to hospital in the next 18 months on account of episodic visual failure but ono each occasion this improved spontaneously without operative interference. Her condition has since remained stationary and when seen five years after the operation? she was well and active with good vision (VAL J.1, VAR J.6) and fields full to confrontation. Her mental state was normal.

Case 10 (U.O.H. 26618).-C.M., a 60-year-old woman, was noticed by her family and friends to be becoming nervous and irritable. Although normally a capable and placid person she became easily upset by trivialities such as whether her family came home later than usual. Small household matters, such as times of meals, caused her undue concern and she complained of constant tiredness. Her symptoms were ascribed to the strain of air-raids and to worry about her husband who was on active service. A rest in the country was advised and she seemed to improve. Soon afterwards, however, she found she was unable because of failing memory and increasing lethargy to manage the large amount of voluntary war work she was engaged in and even her correspondence was neglected. The letters to her husband, formerly cheerful and informative, became short and disjointed, she was irritated by the servants, forgot what she was doing, had to write everything down, and could concentrate on a subject for only a few moments. Her family noticed that although she could recall and describe events which had occurred years 
before, daily happenings were often forgotten by the evening. She rested often and fell asleep at the slightest opportunity.

Some months later she began to lose her way about the house, although she could still recognize faces and carry on a reasonable conversation. She complained of stiffness in the legs and was from time to time incontinent of urine. There was slight headache but no visual symptoms and the total length of history was one year. Her menstrual history was normal and she had two children.

On examination at that time she could remember neither the year nor her whereabouts. She understood and obeyed simple commands such as "close your eyes", but more complicated instructions were ignored. She had no idea of current events and could not do simple mental arithmetic.

She was unable to recognize a photograph of her son although she did recognize her husband. Speech was slow and deliberate and she would often change the subject in the middle of a sentence or break into poetry. She was able to name only one of six common objects and perseverated frequently. She did not know how to hold a fountain pen or a match. Her mood was apathetic but cheerful and she was always gracious and courteous when spoken to.

Physical examination revealed a normally proportioned woman who was not wasted and did not look ill. There were no signs of endocrine abnormality, hair, skin, and sexual development being compatible with her age.

In the central nervous system there was no anosmia and the optic discs were rather pale but not definitely abnormal. Vision was J.2 bilaterally and fields were full to confrontation. Field charting was impossible due to lack of cooperation. In the limbs there was weakness and some increase in tone more marked on the left side. Reflexes were all brisk, left more than right, and plantar responses were unobtainable. There was a marked tremor on movement of either hand and no sensory deficit. Blood pressure was $170 / 100 \mathrm{~mm}$. $\mathrm{Hg}$.

Investigations. - A skull radiograph showed a calcified tumour above the sella, which was normal in size.

A lumbar puncture showed clear fluid at normal pressure, with protein, $60 \mathrm{mg}$., and no cells.

A ventriculogram showed that the right ventricle was entered easily, and pressure was $15-17 \mathrm{~mm}$. of water.

Both lateral ventricles were greatly dilated, the right more than the left. The third ventricle was not well filled but a large calcified tumour was seen projecting into it.

Operation and Progress.-The tumour was approached through the right lateral ventricle after reflection of a frontal flap. The right foramen of Munro was distended and a bluish cyst projected through it. After further exposure the cyst was dissected free off the walls of the third ventricle and removed although a portion of it had to be left behind.

Following the operation there was little change in the patient's physical or mental state. She was able to live at home but six months later was readmitted for further aspiration of the cyst. Vision at that time was $\mathrm{R}$ J.12,
L J.10; all limbs were spastic with increased reflexes and extensor plantar responses.

She was admitted for the last time two years after the onset of her illness. There was little change in the physical signs though sie had gained some weight. Vision was J.12 right and left. Ventriculography showed enormously dilated lateral ventricles but no filling of the third ventricle.

An attempt was made to remove the tumour radically but she developed pulmonary oedema and died soon afterwards. The diagnosis was confirmed histologically.

Case 6 (U.O.H. 266283).-H.W., a woman aged 67 years, previously an energetic housewife of average intelligence, was noticed by her husband to be losing her memory. She did not seem able to concentrate on a subject for more than a few seconds and wandered aimlessly about the house forgetting what she had meant to do. She also tended to fall asleep many times during the day and continually complained of tiredness.

Soon afterwards she began to notice visual blurring which at times was severe enough to restrict her vision to hand movements while at other times she could see to read. She consulted an ophthalmologist who found visual acuity reduced to hand movements and pallor of both discs. Field charting showed bilateral central scotomata. Skull radiographs were normal.

No diagnosis was reached and she continued at home gradually losing both her sight and her senses, until nine months from the onset when she was admitted to hospital because she refused to eat or drink.

She had had only slight headache but she complained of increased sensitivity to cold.

There were no significant features in her past or family history. Menses had been normal, and she had borne four children.

At the time of admission to the Churchill Hospital under Dr. Ritchie Russell, she appeared profoundly demented. She lay motionless in bed moaning feebly and resented any attempts to speak to her. She was unable to feed herself and was incontinent of urine.

She knew the names of her relatives but was unable to name the hospital or the year. She thought she was at home in bed, that she was 40 years old, and that both her parents were alive (although they had been dead for 20 years). She had no knowledge of current events and could not attempt tests of mental arithmetic. She could retain five digits forwards but not backwards. She frequently dropped off to sleep during the day and when roused appeared even more confused than usual. There were, however, lucid intervals in which she would converse sensibly, knew she was in hospital, and gave her age and address correctly. She never smiled and her mood was one of apathy and deep depression.

Physical examination revealed a pale and dehydrated woman of normal proportions. The skin was colourless and atrophic, the hair thin, and the sexual development compatible with age.

She was able to appreciate hand movements only in all parts of the field. Both optic discs were atrophic and purils reacted sluggishly to light. There were no other abnormal signs. Blood pressure was $110 / 60 \mathrm{~mm}$. $\mathrm{Hg}$. 
Investigations. - The cerebrospinal fluid was under normal pressure and was without clear cells. Protein level was $60 \mathrm{mg}$. per $100 \mathrm{ml}$, total serum proteins $6 \cdot 1 \mathrm{~g} . / 100 \mathrm{ml}$. (albumin $2 \cdot 85$, globulin $3 \cdot 25$ ).

Haemoglobin was $17.5 \mathrm{~g} . / 100 \mathrm{ml}$., white blood cells $7,000 /$ c.mm. (normal differential), and blood sugar (fasting) $83 \mathrm{mg} . / 100 \mathrm{ml}$.

An insulin sensitivity test showed increased sensitivity by a blood sugar level of $38 \mathrm{mg}$. $/ 100 \mathrm{ml}$. half hour after 1.5 units of insulin.

Blood urea and electrolytes were normal and the blood cholesterol $195 \mathrm{mg} . / 100 \mathrm{ml}$.

Urinary volume was $1,500 \mathrm{ml}$./day, with an average neutral 17-ketosteroid excretion of $2.5 \mathrm{mg}$. $/ 24$ hours.

A skull radiograph showed that the dorsum sellae was thin, without abnormal calcification.

For a lumbar air encephalogram the patient was uncooperative. No definite abnormality was seen, the lateral ventricles were normal, but the third ventricle did not fill well.

Progress.-Two weeks after admission she developed fever and neck stiffness and was found to have a pleocytosis (500 polymorphs/c.mm.) of the cerebrospinal fluid. She was assumed to have a meningitis following the initial lumbar puncture although no organisms were isolated. Treatment with penicillin and streptomycin appeared to have some effect but repeated relapses occurred. Meanwhile her mental and visual state continued to deteriorate and she soon became quite blind. Treatment with cortisone and with thyroid was ineffective and she was transferred after six weeks to a chronic hospital. There she died one year after the onset of symptoms and post-mortem examination showed a large cystic craniopharyngioma which occupied the anterior part of the third ventricle and which histological examination showed to be infiltrated with polymorphs and chronic inflammatory cells. There was slight hydrocephalus, and no signs of meningitis.

Case 11 (U.O.H. 966116).-J.S., an active and successful farmer of 57, noticed the onset of frontal headache following a heavy blow on the head sufficient to knock him unconscious for a few minutes.

From then onwards he felt continually tired and gave up part of his work. His wife also noticed that he was excessively forgetful and that he tended to drop off to sleep after meals. A doctor was consulted and a period of bed rest was advised. His memory seemed to improve for a time, then deteriorated again. He was depressed, sleepy, and disinterested and had to give up his work entirely. He retired to bed at home but shortly afterwards lost all his memory for farming matters, could not recall the date or time, and began to vomit. He refused to eat or drink and his admission to hospital was arranged.

His past health had been normal in every way and he was married with one son.

On examination in hospital he was drowsy and disinterested and his speech was rather slurred. He was unable to say whether he was in hospital or in church and was surprised to hear that the war had ended some years before. He could not remember how he had come to hospital or how he had spent the past few days but remembered the names of his family and the fact that he was a farmer. He was extremely distractable, continually looking round for an opportunity of changing the conversation and tried to avoid questioning by closing his eyes. When pressed for an answer he would say he was a soldier, had been wounded and wanted a rest, and then would change the subject abruptly. He was unable to attempt tests of mental arithmetic but could obey simple commands and was able to read, write, and name simple objects. His vocabulary was normal, he was apathetic, and had no insight into his condition.

Physical examination revealed a well-nourished, normally-proportioned man with a high colour and no evidence of endocrine abnormality. In the central nervous system there was no anosmia, corrected vision was L 6/24, J.6; R 6/12, J.6, and fields were full to confrontation. The optic discs were normal and there were no other relevant findings. Blood pressure was $140 / 80 \mathrm{~mm} . \mathrm{Hg}$. A subdural haematoma was suspected.

Investigations. - In the cerebrospinal fluid (ventricular fluid) pressure was $120 \mathrm{~mm}$., with no cells, and protein $130 \mathrm{mg}$. per $100 \mathrm{ml}$.

A sugar tolerance test was normal.

An arteriogram showed evidence of some hydrocephalus but none of displacement.

A ventriculogram showed moderate hydrocephalus of the lateral ventricles, and a space-occupying lesion on the floor of the third ventricle arising from the hypothalamien area.

Operation and Progress.-A ventriculocisternostomy was performed, and following this there was no $\mathbb{O}$ immediate improvement in the mental state. The patien 8 was disorientated and amnesic for two days after the operation and thought he was in Glasgow. Drowsiness was more marked than before the operation. A few days later, however, he improved, became quite alert, cheerfu and talkative, although still disorientated and confabulating. He was well enough for discharge after a month. For a further three months he remained confused, incontinent, and bedridden at home but then suddenly and dramatically improved, resumed his farming interests, managed his accounts, drove his car, and led a comparatively normal life. He was not incontinent, was free from headache, walked steadily, and his memory served him well. He remained in this state for a year but then drowsiness, memory disturbance, and vomiting returned. He became muddled and incontinent but there was no headache or visual disturbance. He returned to hospital where the findings were the same as those on the previous admission. The tumour was needled, found to be cystic and $60 \mathrm{ml}$. of yellow fluid was withdrawn.

There was transient improvement for a few days, but he then became drowsy again and finally died after a period of coma.

At necropsy the tumour proved to be a craniopharyngioma. The liver showed extensive cirrhosis.

Case 5 (U.O.H. 234340/57).-L.S., a 56-year-old housewife, complained of intermittent frontal headache which was ascribed to hypertension until her family began to notice progressive mental deterioration. She was 
unable to remember her shopping list, neglected her home and personal appearance, and at times became confused as to her whereabouts. She was occasionally incontinent of urine and on some days appeared drowsy and apathetic, while on others she seemed normal and alert. About this time she had a number of attacks of unconsciousness of sudden onset and lasting about 10 minutes. During these seizures she was limp all over and was incontinent of urine. Sometimes the arms jerked. Shortly afterwards she was admitted to hospital as a cerebral tumour suspect. At no time was there any complaint of visual loss.

In her youth she had enjoyed good health and was married but childless. Twelve years previously she had suffered transient right hemiparesis with dysphasia, from which she made a full recovery. It was noticed just before admission that her speech had again deteriorated and that she had difficulty in finding the appropriate word.

On examination she was fully conscious but could not remember the date or the name of the hospital. She was easily flustered and confused and could not cooperate in mental testing. Her mood was apathetic and she never spoke spontaneously to her neighbours in the ward or to the nursing staff. She was incontinent of urine. She could respond to command and speech and vocabulary were normal, although she made a few mistakes in naming common objects.

Physical examination revealed a normally proportioned woman with some facial hirsutes but no other endocrine abnormality. The sense of smell could not be tested but the fundi were normal. The pupils were large and reacted sluggishly to light. Visual acuity was reduced but was not recorded. There was a left homonymous hemianopia and slight weakness in the left side of the face. The remaining cranial nerves were normal. In the limbs there was slight weakness of the left arm and leg but no reflex change or sensory loss. The blood pressure was $170 / 100 \mathrm{~mm}$. $\mathrm{Hg}$.

Investigations.-A skull radiograph showed erosion of the dorsum sellae with suprasellar calcification on both sides of the midline.

A right carotid angiogram showed that the pericallosal artery was slightly elevated and displaced to the right in the anterior part.

The Sylvian group of vessels were elevated. A ventriculogram showed marked dilatation of the lateral ventricles. The anterior part of the third ventricle was elevated and displaced to the left by a mass which extended almost to the foramen of Munro.

The cerebrospinal fluid was faintly turbid but colourless with no cells, and protein, $70 \mathrm{mg} . / 100 \mathrm{ml}$.

An EEG gave a dominant rhythm of 7 to $8 \mathrm{c} / \mathrm{s}$ with random delta waves at $1-2 \mathrm{c} / \mathrm{s}$ in all leads. No consistent focus or asymmetry was present.

Operation and Progress.-The tumour was approached after a right frontal flap and elevation of the frontal lobe. A large purple mass was found presenting on the medial side of the right optic nerve and displacing it upwards and outwards. The mass was incised and the contents removed piecemeal. It was found to extend posteriorly under the right optic tract. As much as possible of the capsule and contents were removed.

Post-operatively the patient appeared a little more alert but remained grossly demented and the left hemianopia and mild left hemiparesis were unchanged. Sight showed some subjective improvement and she was able to walk around the ward. Seizures were controlled by phenytoin.

Three months after operation, however, she again became bedridden and demented and died at home. There was no necropsy but the diagnosis was confirmed histologically on tissue removed at operation.

Case 20 (U.O.H. 3096/37).-C.L., an unmarried woman, had an uneventful medical history until the age of 66 when she noticed that she was having difficulty in reading the number plates on motor-cars. This improved for a time after a visit to the oculist but showed a further sudden deterioration five months later. She noticed that vision to the side was particularly affected.

About this time a number of other symptoms appeared. She had occasional headache, she began to fall asleep during the day whenever she sat down, and felt constantly tired; she was excessively thirsty and her relatives noticed a rapid decline in her mental faculties. Although previously an alert and intelligent woman, she became very absent minded and failed to recognize her friends. She was apparently quite unaware of the time of day, although she talked sensibly about the distant past. She neglected herself and forgot to go shopping, and when her sister came to stay and look after her, she mistook her for her mother who had been dead for 20 years.

In the past she had a normal menstrual history and passed the menopause at the age of 48 . From the ages of 30 to 34 she suffered from frequent severe headaches accompanied by almost total loss of sight in the whole visual field for half an hour. Another episode of headache and visual failure occurred 10 years later but again passed off in a year or two leaving her free from symptoms. She came of a long-lived family, and there was no history of migraine.

When seen three months after the onset of mental symptoms, she was pleasant and cooperative but yawned frequently and tended to fall asleep if conversation lapsed. She was hopelessly confused about the place and date and did not know how long she had been in hospital. Memory for recent events was particularly poor; although she was told the name of the doctor she was unable to recall it 30 seconds later and had constantly to be reminded. Tests of mental arithmetic were performed slowly but accurately, but she was easily distracted. Her mood was normal.

Physical examination revealed a well-nourished woman, looking rather younger than her years. The skin was pale, smooth, dry, and hairless and showed erythema ignis over the shins. Scalp hair was normal but pubic hair was sparse and axillary hair absent. The sexual organs were normal. In the nervous system there was anosmia on the left, hyposmia on the right. Acuity was VAR $3 / 6, \mathrm{~J} .4$, VAL $3 / 12$, J.12, and field charting showed a scotomatous type of bitemporal hemianopia, the scotomata ending sharply at the vertical meridian. 
Fundi were normal and both pupils reacted sluggishly. There were no other abnormal signs apart from conduction deafness in the right ear. Blood pressure was $140 / 90 \mathrm{~mm}$. Hg. Average daily urinary volume was 3 litres and was markedly reduced by pituitrin. She vomited occasionally and had attacks of uncontrollable shivering unaccompanied by change in temperature.

Investigations.-A glucose tolerance test showed, fasting, $95 \mathrm{mg} . / 100 \mathrm{ml}$., three-quarters of an hour after $50 \mathrm{~g}$. glucose, $200 \mathrm{mg}$., and two hours after $50 \mathrm{~g}$. glucose, $154 \mathrm{mg}$.

The cerebrospinal fluid was clear at a pressure of $70 \mathrm{~mm}$. with cells $2 / \mathrm{c}$. mm., protein $50 \mathrm{mg}$. per $100 \mathrm{ml}$. The Lange curve was 0000000000 and the Wassermann reaction negative.

A radiograph of the skull showed slight erosion of the dorsum sellae but no other abnormality.

An encephalogram showed a tumour mass projecting into the anterior part of the third ventricle.

Operation and Progress.-The tumour was approached by the right subfrontal route. The chiasma was postfixed, the pituitary stalk was swollen, and a solid portion of tumour could be seen between the right optic nerve and the internal carotid artery. The tumour was circumscribed, firm, and homogeneous. A biopsy was done but no removal was attempted. The diagnosis of craniopharyngioma was confirmed histologically.

After the operation there was a period of peripheral circulatory collapse, but the next day she improved and a week later vision was left J.2; right, J.4. Polyuria persisted but she was correctly orientated and carried on a sensible conversation. Memory was much improved.

Over the next six months her mental state returned to normal and she was able to lead an active life, although still handicapped by the visual field defect, and by pains in the small joints of her hands.

She died four years after the operation of a cerebral haemorrhage.

\section{Endocrine Abnormalities}

A summary of the relevant history and findings in the endocrine system is set out in Table I. Evidence of severe, long-standing hypopituitarism as shown by small stature or failure to achieve sexual maturity only occurred in one patient, a small, mentally retarded woman with primary amenorrhoea and absence of secondary sexual characteristics.

Ten patients exhibited a milder degree of pituitary or hypothalamic disorder which had been present for some years. Common symptoms were lassitude, decreased tolerance of cold, irregular menstruation, diminished libido, weight gain, polyuria (which was sometimes episodic), and subnormal beard growth. This was confirmed on physical examination by the finding of pale, finely-wrinkled skin, brittle, sparse body hair, and a plump, relatively youthful appearance. However, 13 patients had no definite endocrine symptoms and had no abnormal signs.

Potency was little affected; of the total group of
24 patients, 20 were married and 16 had children. $\frac{\bar{c}}{Z}$ None of the patients had hypertension. In 18 the blood pressure was normal and in three the systolic $\frac{\subseteq}{3}$ pressure was below $110 \mathrm{~mm}$. Hg. Two patients were known to have suffered previously from hypertension but had normal values.

Biochemical investigations were not performed on all patients and gave little additional information. Fasting blood sugar values were low normal, tolerance curves flat; ketosteroids were within the range of normal for age.

\section{Other Clinical Features}

There were few other abnormalities in the central nervous system. Anosmia occurred in five patients, but three were confused at the time of examination. One patient had a lateral rectus palsy. There were is no changes in the limbs apart from one patient who $\overrightarrow{0}$ had symmetrically increased reflexes and extensor plantar responses.

Three patients suffered from seizures, two were grand mal in type with convulsive movements of all limbs. One had falling attacks with sudden loss of i power in the legs and momentary loss of consciousness.

Cerebrospinal fluid was examined in 19 patient In five it was normal, in 10 the protein content was raised from 50 to $100 \mathrm{mg} . / 100 \mathrm{ml}$., and in foup from 100 to $170 \mathrm{mg} . / 100 \mathrm{ml}$.

In three patients there were recurrent episodes of sterile meningitis with polymorphonuclear re sponse in the cerebrospinal fluid. In two the meningitic episode occurred post-operatively and in one following a lumbar puncture. No organisms were grown despite repeated cultures.

Skull radiographs showed abnormal calcification above the sella in 13 with moderate or great enlargement of the sella in six.

\section{Follow-up}

It was possible to obtain information about 23 out of the 24 patients in this series, and the details are set out in Table II. Two treated and three untreated patients were alive 10 or more years later although two of these were severely demented. Three died in the immediate post-operative period in a state of peripheral circulatory failure. Six died within a year of operation and two within five years of operation.

\section{Discussion}

The Visual Symptoms.-It is clear from the number of cases in this series and from other reports (Pennybacker, 1949; Love and Marshall, 1950) that tumours of Rathke's pouch, although of developmental origin, may present at any time from 
TABLE II

CLINICAL FEATURES, RADIOLOGICAL FINDINGS, AND SITE OF TUMOUR

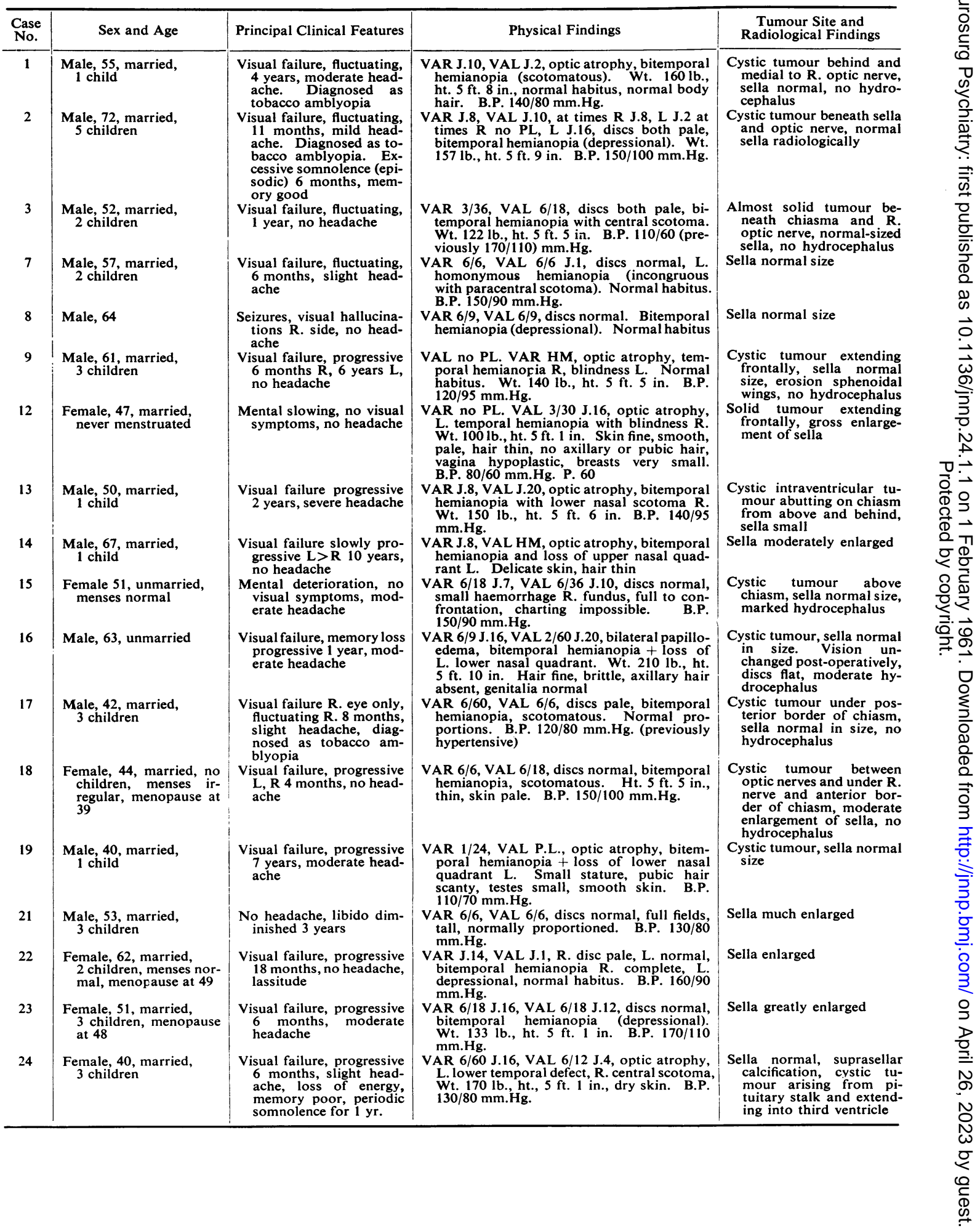


childhood to old age, and that in one patient in four symptoms first occur after the age of 40 years. The clinical features at this age differ markedly from those in younger patients, but visual disturbance remains a common symptom. It may be undetected because in the early stages it may affect only one eye, because the patient may be unable to give an adequate account, or because of the absence of abnormality on retinal examination. Occasionally vision is lost abruptly and a patient has been described in whom total or permanent blindness occurred in a few hours (Wertheimer and Corradi, 1957), a sequence of events suggesting a vascular occlusion. Much more commonly a slow decline in visual acuity affecting one or both eyes takes place over months or years before the patient seeks advice. The average for the present series was 27 months.

The retinal appearances are often misleading; although a proportion of cases show optic atrophy and others a questionable pallor of the discs, in many there is no abnormality. Papilloedema is common in young patients with third ventricular obstruction

but rare after 40 years of age. Of 100 cases of all ages reported by Love and Marshall (1950) papilloedema was present in 28 and optic atrophy in 21. In the series of Wagener and Love (1943), the discs were normal in six, pale in nine, atrophic in six and oedematous in eight, all patients with papilloedema being under 25 years of age. There was no correlation between the presence of optic atrophy and the situation of the tumour. The ophthalmoscopic findings in the present series and in these and other reports (Wertheimer and Corradi, 1957) are in general agreement.

Much more consistent changes are found in the visual fields, and they emphasize the importance of quantitative perimetry in diagnosis. Many different varieties of field change have been described, among them bitemporal hemianopias, homonymous hemianopias, concentric contractions of fields, and central or paracentral scotomata. Bitemporal defects, usually asymmetrical, are the commonest finding, occurring in about half the patients, homonymous defects in about a quarter (Love and Marshall, 1950). The frequency of central scotomatous defects is very variable but in some series they occurred in about a third of patients, usually in combination with peripheral field changes (Wagener and Love, 1943).

The position of the tumour as far as can be determined by clinical, radiological, and operative findings, bears no constant relation to the type of field defect. Because of variations in size and in site of origin and because of inconstant fixation of the chiasm, no part of the optic nerve, chiasm, or tract is particularly vulnerable. It might be supposed that central scotomata would be produced by anteriorly placed tumours affecting the optic nerves, bitemporal hemianopias by tumours at the chiasm, and homonymous defects by tumours behind the chiasm. The most that can be said is that anteriorly placed tumours are usually associated with bitemporal defects and posteriorly placed tumours, sometimes with homonymous defects, while central scotomas may occur with tumours in any situation (Wagener and Love, 1943).

Since one eye is usually more severely affected than the other the compressive lesion is probably towards one or other side of the chiasm rather than in its centre, and the finding in severe cases of one blind eye with a temporal hemianopia in the other is in accord with a lesion of the anterior chiasmal angle. Cases 9 and 12 in the present series, which presented this field defect, both had anteriorly situated tumours.

It has been said that in cases of bitemporal hemianopia the lower temporal quadrants are affected first, indicating a lesion affecting the chiasm from above (Hughes, 1954). In the present series, however, the upper and lower quadrants were affected with equal frequency. Nor was radiological enlargement of the sella associated with any $\frac{\rho}{\mathbb{P}}$ particular type of field change. Scotomatous $\varrho$ 구 defects were as common as the depressional variety in the present series and this may be misleading unless the peripheral isopters are charted. These are seldom full and usually show some temporal $\overrightarrow{0} \cdot \vec{\theta}$ indrawing. In scotomas near the fixation point there is usually a sharp demarcation at the vertical meridian which suggests a lesion of the fibres from the nasal side of the macula running in the posteroinferior border of the chiasm. Four such cases occurred. Operation in Cases 17 and 13 confirmed a tumour in this situation, but in Cases 1 and 18 the tumour was anterior to the chiasm in relation to the optic nerve.

Central scotomas were first reported by Critchley and Ironside (1926) and have been repeatedly observed since then. The suggestion has been made that they are caused by traction on the optic nerves as the chiasm is displaced by the tumour, or by angulation of the nerves at the optic foramina (Hughes, 1954). Scotomas may be found in association with both temporal and homonymous field loss. Of the four patients in this series who had central scotomas only two were operated on. In one the tumour was found under the chiasm and optic nerve on the side of the scotoma (Case 3) and in the other the tumour was pressing on the chiasm from above and behind (Case 24).

Both visual acuity and fields are subject to 
remarkable fluctuations and these may give rise to diagnostic difficulty, especially when the field loss is central or centrc-caecal. Three patients in the present series were thought to have tobacco amblyopia or retrobulbar neuritis because of a unilateral diminution of acuity recovering in a few weeks, and this mistake has been made before (Witt, MacCarty, and Keating, 1955).

Changes also occur in the visual fields and cases have been reported in which a bitemporal defect became homonymous (Holloway, 1935). Fluctuations in the visual state may be accompanied by hypothalamic changes, by the transient appearance of somnolence, polyuria, or memory disturbance, or sometimes by reversible EEG changes (Norstrand, 1955). The cause of these fluctuations is not clear. It may be due to variations in size of a cystic tumour, but it was also observed in tumours which were almost entirely solid (Case 3 of the present series). Local oedema is perhaps the likeliest explanation and is probably on a vascular rather than an inflammatory basis, since histological examination seldom shows any cellular infiltration of the tumour.

The Mental Symptoms.-The finding that over half the patients in this series suffered from impairment of memory and that eight patients presented the appearances of advanced organic dementia shows that mental symptoms are of considerable diagnostic importance although they have been comparatively neglected in the literature.

Farnell (1911) described a pituitary adamantinoma in a woman of 43 . She suffered from episodes of amnesia and extreme sleepiness, and was often confused and disorientated. Impairment of memory and periods of drowsiness were noted in a woman of 27 reported by Critchley and Ironside (1926). Necropsy confirmed the presence of a craniopharyngioma but there was no hydrocephalus. In a patient of Beckmann and Kubie (1929), a man of 43, a Korsakow delirium with amnesia and confabulation occurred post-operatively. Cushing (1930) noted personality change in one patient associated with a period of somnolence, polyuria, and emotional negativism, all of which he regarded as due to hypothalamic damage. Dott (1938) described two patients aged 37 and 42, in whom amnesia and disorientation were prominent symptoms. One of these had a tendency to emotional lability and disinhibition. Of 100 cases reviewed by Love and Marshall (1950), four had psychiatric features, consisting of memory loss, confusion, defective judgment, and episodes of mania. The changes were thought to be due to pressure on the frontal lobes by the tumour. Seizures occurred in four patients and in two there was an uncinate aura.
Comprehensive tests of mental function were undertaken by Williams and Pennybacker (1954) in four cases with tumours in the region of the hypothalamus. Three were craniopharyngiomas, and the patients showed marked defect of memory and learning with confusion and confabulation, but preservation of other features of intellect and judgment. The authors showed that the amnesia was probably the result of a local hypothalamic lesion and was independent of raised intracranial pressure. In a review of patients with craniopharyngioma, $72 \%$ of patients with growths involving the third ventricle showed some memory impairment but none of the patients in whom the tumour was further forward. The most marked changes were found in elderly patients.

Norstrand (1955) reported the clinical features of six patients over the age of 40 with craniopharyngiomas. In four there were mental symptoms; one was depressed, one uncooperative and apathetic, one confused and disorientated, and one had a period of abnormal behaviour post-operatively. Depression was noted in two out of 65 cases reviewed by Wertheimer and Corradi (1957) and was accompanied by headache and loss of weight. Memory changes were not recorded but somnolence was common $(22 \%)$, one patient having attacks of irresistible yawning. The basal metabolic rate was normal. Tiberin, Goldberg, and Schwartz (1958) reported two cases aged 60-65 with advanced organic dementia. One had seizures and some features of hypothalamic disorder, and in the other the only localizing sign was optic atrophy.

There is a marked similarity in the case histories of the mentally affected patients in this series. In all, the earliest symptom was a defect of recent memory often fluctuating and due to a disturbance of attention and of the interpretation and elaboration of sensory information. This loss of retentive capacity was associated with episodes of somnolence, confusion, disorientation, and sometimes with confabulation. Mental testing showed a disproportionate difficulty with tests involving the repetition of stories after a short interval, the retention of new impressions, and the ability to learn new habits. Tests of immediate recall such as the repetition of a number of digits were performed much more easily. The patients appeared more severely disturbed in hospital than at home because of their inability to comprehend new surroundings or new faces. They were often difficult to rouse from sleep but once awakened were cooperative but extremely distractable. Vocabulary and distant recall were usually preserved. Social behaviour remained appropriate.

More severely affected patients showed in addition 
to the memory defect a general progressive deterioration in intellect with narrowing of interest, neglect of personal appearance, apathy, and emotional lability, which differed in no way from the dementia seen in many types of degenerative brain disease. This degree of mental disturbance occurred mainly in elderly patients and was associated in all but one case with considerable dilatation of the lateral ventricles. There was less tendency to fluctuation than in the younger patients. The difficulties of diagnosis in elderly patients may be great since the optic discs may be normal and visual acuity and field testing impossible because of lack of cooperation.

It seems likely that the early memory disturbance described above is due to a lesion of the hypothalamus or of its connexions with the hippocampal system (Russell, 1959). Protracted cases of Wernicke's encephalopathy, which usually exhibit clouding of consciousness and amnesia in addition to ocular abnormalities, show consistent vascular changes in the mamillary bodies and around the third ventricle and aqueduct (Gamper, 1928; Campbell and Biggart, 1939; Meyer, 1944). Furthermore, bilateral removal of the hippocampus produces a selective and profound amnesia for recent events, although other aspects of intelligence are spared (Scoville and Milner, 1957), and cases with bilateral hippocampal sclerosis or atrophy of the fornices without other cortical abnormalities are said to exhibit a similar state (Schenk, 1959).

Cairns (1952) showed that various lesions in the posterior part of the third ventricle, such as a tumour of the pineal gland or thalamus, postoperative oedema or damage to the upper brainstem, may produce not only amnesia but also various disturbances of consciousness, such as coma with tonic fits, petit mal seizures, hypersomnia, and akinetic mutism. He regarded the functions of consciousness, wakefulness, and memorizing as closely related and all controlled by a mechanism in the hypothalamus. This view is confirmed in the present series in which somnolence and amnesia appeared to go together, showing marked fluctuations both spontaneously and as a result of aspiration of a cystic tumour.

In the patient with a craniopharyngioma of the third ventricle reported by Cairns, Oldfield, Pennybacker, and Whitteridge (1941), a state of speechlessness and of muscular relaxation resembling sleep but with retention of purposive eye movements, was accompanied by a sleep-like EEG activity. The patient and the electrical record were dramatically restored to normal on aspirating the cyst, but there was complete amnesia for the akinetic period. Mental symptoms may show a similar sudden improvement after aspiration (Foerster and Gagel, 1933). Conversely, relief of intracranial pressure alone or by a ventriculocisternostomy frequently brings about no change in somnolence or in the mental state, indicating that raised pressure alone is not responsible (Cairns, 1952).

To explain the close relationship of disturbance of consciousness and memory with the upper brainstem it has been suggested that the hypothalamus by means of its thalamic connexions and by the fronto-hypothalamic fibres play a part in the laying down and facilitation of memory and learning patterns in the cortex and may constitute a mechanism which can quickly activate or suppress large areas of the cortex (Obrador, 1943). There is some localization even within the hypothalamus, amnesia being commoner in lesions such as craniopharyngiomas lying in the floor and sides of the ventricle than in those further forward, such as a colloid cyst of the third ventricle (Cairns and Mosberg, 1951).

On the other hand, some authors deny that amnesia has any localizing significance and state with some pathological evidence that it is related more to diffuse brain damage and in particular to the age of the patient (Bleuler, 1951; Carmichael $\frac{}{\mathscr{D}}$ and Stern, 1931).

Patients showing a global dementia with decay of all aspects of intellect and personality did not show $\mathbb{D}$ marked fluctuations either spontaneously or as å ำ result of treatment. Encephalography or ventriculo-릴 graphy in these patients showed generalized dilata- $\vec{c}$ tion of the lateral ventricles, sometimes with an obstruction to passage of air in the third ventricle, and the dementia probably resulted from cortical atrophy consequent on chronic obstruction of the third ventricle, in a brain already affected by age and arteriosclerosis. By a similar mechanism a tumour in the posterior fossa may sometimes present as an organic dementia in old age. It is significant that while circumscribed memory defect may occur in young patients (Williams and Pennybacker, Case 3), severe generalized dementia was seen, especially in the elderly. Extension of the tumour into the frontal lobes has been suggested as a factor, but was not apparent in the patients in this series coming to necropsy. Neither thyroid nor vitamin treatment has been effective even when the patient has been clinically hypothyroid (Case 8 , present series).

\section{General Observations}

Since craniopharyngiomas are of developmental origin and may remain clinically silent until middle life or later, the rate of growth must be extremely slow or intermittent. Some cases in the present series were observed without treatment for periods 
of 20 years without clinical or radiological change, and it is likely that a number remain symptomless and undiagnosed throughout life. A period of rapid growth with the compression of neighbouring structures may be followed by a prolonged period of inactivity during which no new symptoms develop. In two cases in the present series transient premonitory symptoms occurred during the third decade, in one a few weeks of polyuria and in the other a period of intense paroxysmal headache and vomiting. These episodes resolved without treatment and no further symptom occurred for 20 years. These striking fluctuations, which may affect visual, mental, or hypothalamic symptoms, make prognosis and the assessment of operative treatment very difficult, and suggest that surgery should be as conservative as possible, being restricted to those cases with signs of advancing chiasmal compression or of obstructive hydrocephalus. Since the bulk of a craniopharyngioma is usually cystic, an increase in size is probably brought about by an increase in volume of cyst contents, but there is little to show how this comes about. There is seldom any evidence of recent haemorrhage nor any microscopic evidence of inflammation of malignant change though this may occur (Wertheimer and Corradi, 1957). It is seldom possible to remove the entire tumour and the operative mortality of attempted radical removal is considerable (Critchley and Ironside, 1926; Grant, 1948). Since the reaccumulation of fluid after partial removal bears little relation to the amount of tumour removed, it may be wisest to carry out a limited excision of the cyst wall with aspiration of the contents and this procedure may be combined with ventriculocisternostomy. In Case 4 of the present series, repeated aspiration of the cyst alone was enough to abolish mental and visual symptoms for five years. It may be impossible to distinguish on clinical or radiological grounds between a craniopharyngioma and a pituitary adenoma, a difficulty which arises most frequently in middle-aged patients. The distinction is of more than academic importance in view of the favourable response of adenomas to $x$-ray therapy. The diagnosis is usually clear at operation, but since occasionally adenomas may be cystic and craniopharyngiomas solid, only histological examination is conclusive. The contents of the cyst may escape into the cerebrospinal fluid circulation either spontaneously or post-operatively and was the probable cause of the sterile meningitis in three patients in the present series. In three others the onset of symptoms was related to a head injury and this association has been noted before (Cushing, 1932).

In conclusion, it is evident that a cranio- pharyngioma should be considered in a patient of any age with symptoms suggesting compression of the chiasma, particularly when the visual field defect is asymmetrical, fluctuating, or scotomatous, and even when the skull radiograph shows no calcification (Love and Marshall, 1950). Craniopharyngiomas and tumours of the third ventricle should also be considered in the differential diagnosis of elderly patients with memory defect, somnolence or generalized organic dementia without obvious neurological signs, and particular note taken in such cases of any disturbance of visual acuity or fields.

\section{Summary}

The clinical features of 24 middle-aged and elderly patients suffering from craniopharyngiomas are described with particular reference to visual and mental symptoms.

Reduction in visual acuity or abnormality in visual fields occurred in all but one patient and there was much variation in the type and extent of field defect. Fluctuations in the visual state were a common and striking feature.

Mental changes were noted in half the patients and in some were the dominant feature. Six cases are described.

The natural history of the tumours and the mode of production of visual and mental symptoms are discussed.

\section{REFERENCES}

Beckmann, J. W., and Kubie, L. S. (1929). Brain, 52, 127.

Bleuler, M. (1951). Brit. med. J., 2, 1233.

Cairns, H. (1952). Brain, 75, 109.

- and Mosberg W. H. (1951). Surg. Gynec. Obstet., 92, 545 Oldfield, R. C., Pennybacker, J. B., and Whitteridge, D. (1941). Brain, 64, 273.

Campbell, A. C. P., and Biggart, J. H. (1939). J. Path. Bact., 48, 245.

Campbell, A. C. P., and Biggart, J. H. (1939). J. Path. Bact.,
Carmichael, E. A., and Stern, R. O. (1931). Brain, 54, 189.

Critchley, M., and Ironside, R. N.(1926). Ibid., 49, 437.

Cushing, H. (1930). Lancet, 2, 119 and 175.

(1932), Intracranial Tumours. Thomas, Springfield, Illinois.

Dott, N. M. (1938). In The Hypothalamus, by Le Gros Clark, W. E., Beattie, J., Riddoch, G., and Dott, N. M. Oliver \& Boyd, Edinburgh.

Farnell, F. J. (1911). N.Y. med. J., 93, 462.

Foerster, O., and Gagel, O. (1933). Z. ges. Neurol. Psychiat., 149, 312. Foerster, O., and Gagel, O. (1933). Z. ges. Neurol. Psych

Gamper, E. (1928). Dtsch. Z. Nervenheilk, 102, 122

Grant, F. C. (1948). J. Amer. med. Ass., 136, 668.

Hughes, B. (1954), The Visual Fields, 1st ed. Blackwell, Oxford.

Love, J. G., and Marshall, T. M. (1950). Surg. Gynec. Obstet., 90, 591. Meyer, A. (1944). J. Neurol. Neurosurg. Psychiat., 7, (n.s.), 66.

Norstrand, I. F. (1955). Neurology, 8, 558.

Oorstrand (1943).J. Neurophysiol. 6,81.

Obrador, S. (1943). J. Neurophysiol., 6, 81. 590.

Pennybacker, J. B. (1949). Edinb. med. J., 56, 590. Russell, W. Ritchie (

Press, Oxford.
Schenk, V. W. D. (1959). In Recent Neurological Research, ed. A. Biemond. Elsevier, Amsterdam.

Scoville, W. B., and Milner, B. (1957). J. Neurol. Neurosurg. Psychiat.

Tiberin, P., Goldberg, G. M., and Schwartz, A. (1958). Neurology (Minneap.), $8,51$.

Wagener, H. P., and Love, J. G. (1943). Arch. Ophthal. (Chicago), 29, 873 .

Wertheimer $\mathbf{P}$, and Corradi, M. (1957). Neurochirurgie, 3, 3.

Williams, M., and Pennybacker, J. B. (1954). J. Neurol. Neurosurg. Psychiat., 17, 115.

Witt, J. A., MacCarty, C. S., and Keating, F. R. (1955). J. Neurosurg. 12, 354. 